\title{
Editorial Introduction: Judgement and Embodiment
}

\author{
Ada S. JaARsma and Alexis Shotwell
}

The image at the beginning of this special issue- "Members of the Search Committee" by Kate M. S. Hoffman-is a photograph of a moment during an exhibition called "Art School" that took place in the gallery, Human Resources, in Los Angeles in summer 2014. In this exhibition, Hoffman performed a series of works titled, as a whole, "Make It Work," consisting of the many and varied art projects that she had planned to create over a period of five years-projects that were never realized because of unsuccessful proposals, lack of permission or resources, and the need to spend hundreds of hours crafting grant, residency or job applications. Over the span of three days, Hoffman created the very projects she had envisioned, albeit now in the context of an exhibition that drew attention to the constrictions and fated energies that characterize so much of the daily experiences of artists.

Hoffman ended the performance by printing out every application material she had produced for the "job market" in higher education over the past year: cover letters, CVs, teaching philosophies, samples of student work, samples of her own work. Translating these electronic materials into tangible ones, Hoffman dipped each document in beeswax. As she dipped them repeatedly in the wax, each document gained a certain weight and a transparency that merged its front with its back.

No longer waiting for a verdict by search committees or judges, in this performance Hoffman's materials become objects of substance, in and of themselves - objects that can be held up to the light, touched and smelled, or otherwise interacted with. Each beeswax document testifies, at the same time, however, to the larger context of adjudication, as well as to the inequitable conditions of possibility for artistic production. In an art world in which men are exhibited on average seventy percent of the time, thereby achieving gallery representation as well as wide-ranging forms of social capital, ${ }^{1}$ women (who constitute seventy percent of all art majors)

\footnotetext{
${ }^{1}$ See Steinhauer, who points out that "it's also important to note that on average, the constituents of MFA programs are between $65 \%$ and $75 \%$ women. And then the gallery system is $70 \%$ men. This fact makes the imbalance even more egregious. It's not as if there are fewer women wanting to be in the art world - there are more, if we take grad
} 
occupy much less expansive spaces of production, recognition and legitimation. ${ }^{2}$ And yet the viability of art-making requires artists to participate in competitive applications, despite or in spite of such asymmetries. As Hoffman puts it: "What happens to all these project proposals? They are certainly worth making and do not die with that rejection letter."

In a way, the creation of Hoffman's proposed projects - in the course of three days, and in a re-envisioned context - might be seen as a repudiation of judgement as such. Rather than emerging because a successful grant application resulted in the requisite resources for their creation, for example, these various projects took place through Hoffman's own creative problem solving, as she adjusted the projects to the limited time and space of the exhibition. This kind of refusal-a refusal of the exclusionary structures of judgement-resonates with many formulations of feminist critique. Where judgement serves to reinforce or even reify the status quo, feminist methods of critique work to identify and subvert the normalizing force of judgement. Such methods range from the genealogical diagnoses of medicalizing practices, as demonstrated by Adam Dylan Hefty's essay in this special issue, to the feminist science studies analysis of the trope of the technophobic librarian, as demonstrated by Scout Calvert. Hefty's essay, "Cultivating a New Normal: Mood Disorders and the Managed Self," scrutinizes the emergence of the category of the mood disorder, examining the ways in which managed forms of selfhood lead to internalized, as well as public, frameworks of normal and abnormal. Calvert's essay examines how the work of librarianship is gendered, particularly in terms of emotion work, and offers openings for thinking about how embodiment can give us more adequate understandings of library practices.

Shifting focus to the embodied performance of Hoffman's threeday exhibition, we could also, however, see her various creations as an affirmation of judgement. If the mode of judgement described above aligns with exclusionary norms and practices that call out for feminist critique, we can also follow feminist arguments that affirm an entirely other mode of judgement: namely, the intersubjective and dialogic

school as a bellwether. So, this means that men are being exponentially taken more often than women for representation in galleries." Such statistics have led to projects like Micol Hebron's recent collaborative "Gallery Tally" project, found on Hebron's tumblr site, which invites artists to produce posters that represent the statistics of local commercial gallery spaces. For reviews of the Gallery Tally project, see Broder Van Dyke, who points out that "Looking at 300 galleries, which include more than 2,600 artists, the Gallery Tally found $70 \%$ of the artists represented were male." See also Sette.

${ }^{2}$ For data about Canadian art students, see the 2011 report from the Association of Universities and Colleges in Canada. Women compose almost $70 \%$ of the student population in visual and performing arts (14). 
judgement that is necessary for the very possibility of critique. From this perspective, the reified norms of the status quo, enacted for example by judges who consistently and disproportionately choose to valorize the art by men, only resemble judgement and are better described in terms of prejudice or pre-judgements. While it acts and sounds like judgment, in other words, this kind of pre-judgement is actually the reiteration of internalized, often problematic, assumptions. On this account, the tasks that arise for feminist critique include cultivating allergies to such assumptions, as well as cultivating the capacity for undermining and countering prejudice in the name of judgement. Along these lines, in this issue Suze Berkhout offers generative insights from the too-rare case of philosophical fieldwork. Berkhout analyzes the case of medical practitioners whose settled pre-judgement of their patients as "bad subjects" creates a socially-situated looping effect with particular harms.

Consider, then, how Hoffman's beeswax objects invite spectators to reach out and interact with them, even read them, likely prompting conversations with each other or with Hoffman about the performance, the exhibition, and other salient aspects of the situation like the broader art world itself. Hannah Arendt describes the capacity for judgement that arises through this kind of exchange about aesthetic taste as an "enlarged mentality." Arendt explains that "this enlarged way of thinking, which as judgement knows how to transcend its own individual limitations... cannot function in strict isolation or solitude; it needs the presence of others 'in whose place' it must think" (220). As Arendt explains it, judgement is the name of the action that calls out prejudicial assumptions as problematic and in need of resistance, but judgement is only possible through the plurality of the common space in which we live together. Plurality, she argues, is necessary to provoke our attention to the limits of our own subjective thoughts or experiences, as well as to the limits of prevailing norms.

We find close scrutiny of the hope that thinkers like Arendt place in judgement in Katy Fulfer's essay, "Embodied Judgement and Hannah Arendt: From Boethius and Huck Finn to Transnational Feminisms." Tracking the feminist debates about the degree to which Arendt's account of judgement is useful for engaging in cross-cultural dialogue, Fulfer lays out the stakes of this discussion, making a case for the emergence of meaning-making in contexts of disenfranchisement, oppression and lived contradictions. Similarly, Frances Bottenberg examines the stakes of gendered norms governing women's expression of emotion, arguing that we can shift the epistemic and ethical standards for judging the appropriateness of expressing particular emotion.

Especially when we start to reflect on the relations between judgement and embodiment, however, as each essay in this special issue does, questions arise about the capacity of intersubjective dialogue to do 
justice to the plurality of embodied lives. Should understanding be an ideal to which we each should strive to attain through dialogue with others? Or should "understanding" be exposed as a provisional, often problematic, ideal because it poses asymmetrical demands on differently embodied persons? Anna Mudde's essay, "Embodied Disagreements," elaborates these questions, positing the importance of rejecting understanding in situations when understanding as an ideal requires someone to internalize the harmful norms and social worlds of another.

The debates that open up between the articles in this issue ask us to reflect on the ways in which embodiment and judgement misalign (reinforcing, rather than resisting, violent and discriminatory norms), as well as reflect on the ways in which the relations between embodiment and judgement enable the possibility of resistance. In terms of the latter, we can look to bodily practices that make new capacities of judgement possible: the cultivation of senses that are allergic to prejudicial forms of power, for example, and are attuned to non-oppressive relational dynamics. As B. McClure deftly argues, in an analysis animated by firstperson as well as ethnographic reflections on salsa dancing, some practices of co-produced bodily movement (such as social dancing) can offer simultaneously affirmative and normalizing practices. Fundamentally, however, McClure argues for attending to what it means to be a body with other bodies as a practice of shifting the context and possibilities for judgement in potentially liberatory ways. Similarly grounded in first-person practice, Katja Pettinen offers a rich ethnographic examination of how skill is enacted and taught in the martial art Taijutsu. Pettinen shows that instead of trying to locate skilled practice in a region of the brain or some idea of "muscle memory," we might better become attuned to a complex co-production of our sensorial systems, judgment practices, and socially-situated enactments of skills.

This special issue explores feminist concerns about domination and discrimination (judgements about embodiment), on the one hand, and creative and affirmative becoming, on the other (judgments with embodiment). The articles stage, elaborate and complicate long-standing philosophical positions on the nature of judgement and its relation to embodied and situated lives. What emerges from these essays are sustained reflections, at times consonant and at other times contestatory, on the ramifications of methodological choices themselves. Ranging from sustained ethnographic analysis to genealogy and deconstruction, the essays demonstrate the ways in which our capacity for scrutinizing judgement is intimately linked with our own intellectual practices, training and interests. The productive tensions that arise between the essays raise the stakes for our own commitments to critical, as well as somatic, practices. 
This issue also includes a Book Encounter by Corijn van Mazijk on Maxine Sheets-Johnstone's 2009 The Corporeal Turn and several of her more recent papers. Mazijk's essay discusses Sheets-Johnstone's 30 years-long philosophical study of the broad interdisciplinary developments concerning questions, concepts, and relationships that derive from and center on the body and bodily life. Sheets-Johnstone's writings deal with a remarkably wide array of topics within philosophy, biology, cultural studies, and even neuroscience. The Corporeal Turn's purpose is to reconsider how we should look at life prior to engaging ourselves in dogmatic empirical research and should thus be of great importance to any philosopher or scientist interested in first person methodology.

Finally, this issue presents four Book Encounters on recent publications in the field of continental philosophy. Jérôme Melançon discusses Merleau-Ponty's recently published 1952-1953 lectures at the Collège de France on the literary use of language and on the world of expression. Martin Thibodeau then discusses Tom Rockmore's new book on aesthetics: Truth and Art after Plato, while Maxwell Kennel assesses Daniel Colucciello Barber's 2014 book on Deleuze and the Naming of God: Post-Secularism and the Future of Immanence. To end this issue, Chiara Piazzesi assesses the collected essays on love published by philosophers, linguists, sociologists, economists, and writers in the volume L'amour toujours?

\section{Works Cited}

ARENDT, Hannah. "The Crisis in Culture: Its Social and Political Significance." Between Past and Future. New York: Penguin Books, 2006. 194-22.

Association of Universities and Colleges of Canada. "Trends in Higher Education: Vol.1-Enrolment." Ottawa, 2011. 14-15.

BRODER VAN DYKe, Michelle. "Where Are All of the Women Artists?" Buzzfeed News. 3 April 2014. Web. 15 Nov. 2014.

Hebron, Micol. "A Call for Gender Equality in the Arts." GallyTally Tumblr. Web. 15 Nov. 2014.

SETTE, Maria Teresa. "Transforming data into online protest art." Digital Women UK: Training Connecting Campaigning. 1 Nov. 2014. Web. 15 Nov. 2014.

STEINHAUER, Jillian. "Tallying Art World Inequality, One Gallery at a Time." Hyperallergic: Sensitive to Art and its Discontents. 27 March 2014. Web. 15 Nov. 2014. 